\title{
La tendencia hacia la hibridación en el macrogénero extraordinario durante la era hipertelevisiva. Casos de estudio: Galáctica: estrella de combate , Juego de Tronos y American Horror Story The trend towards hybridisation in the extraordinary macro-genre during the hyper-television era. Case studies: Battle Star, Game of Thrones and American Horror Story
}

Irene Raya Bravo, Universidad de Sevilla - iraya@us.es

Resumen

Durante el nuevo milenio se ha transformado económica y tecnológicamente el ecosistema mediático, lo que sin duda ha afectado en la estructura de los géneros y formatos televisivos tradicionales. En esta nueva era hipertelevisiva también ha aumentado significativamente la producción de series, sobre todo en el mercado estadounidense, que exporta la mayor parte de sus contenidos de ficción internacionalmente. Muchas de estas producciones se engloban dentro del macrogénero extraordinario, es decir, están relacionadas con contenidos de ciencia ficción, fantasía y terror. No obstante, a diferencia de lo que ocurría en etapas televisivas precedentes, gran parte de estas propuestas se caracterizan por la fusión de contenidos y estructuras asociadas a otras convenciones genéricas, de manera que los límites entre géneros se han borrado, mezclando conceptos ajenos entre sí de forma completamente novedosa. En el presente estudio se examinan, desde una perspectiva cualitativa dentro del análisis textual, tres casos de series asociadas a las tres formas genéricas básicas -Galáctica: estrella de combate, vinculada a la ciencia ficción, Juego de Tronos a la fantasía y American Horror Story al terror- con la intención de observar esa tendencia hacia la hibridación en las narraciones extraordinarias.

\section{Palabras clave}

Televisión, hibridación, género, ciencia ficción, fantasía, terror.

\section{Abstract}

During the new millennium the media ecosystem has been economically and technologically transformed, affecting the structure of traditional television genres and formats. Moreover, the production of television drama, especially in the US market, which exports most of its fiction productions around the world, has significantly increased in this new hipertelevision age. Many of these productions are included in the extraordinary macrogenre, meaning that they are related to science fiction, fantasy and horror contents. However, in opposition to past television times, most part of these proposals mix concepts and styles from other genres in a new way, blurring the conventional boundaries. This paper examines three television drama shows associated with science fiction, fantasy and horror -Battlestar Galactica, Game of Thrones and American Horror Story, respectively-, from a quality perspective, with the aim of analyzing the trend toward hybridization in extraordinary storytelling.

Keywords

Television, hybridization, genre, science fiction, fantasy, horror.

Sumario

1. Introducción. 2. La hibridación de géneros en la hipertelevisión. 3. Los dramáticos en el nuevo milenio. 4. Las series extraordinarias en el nuevo ecosistema mediático. 5. Metodología. 6. Resultados. 7. Conclusiones. 8. Bibliografía. 


\section{Introducción}

Durante las últimas décadas se ha producido un gran aumento de la producción de ficción televisiva en el contexto estadounidense, lo que también se ha reflejado en la creación de numerosas series de ciencia ficción, fantasía y terror. La proliferación de propuestas se ha materializado en todo el ecosistema mediático televisivo, ya que tanto las networks como los canales de pago o las nuevas plataformas de Internet encuentran en estos programas una estupenda oportunidad para interesar a un amplio espectro de audiencia. Las series de contenido inverosímil han dejado de ser unas cuantas obras para un público minoritario, transformándose por el contrario en una oferta amplia para una audiencia significativa y fragmentada con intereses dispares.

La televisión acoge la herencia de la literatura y el cine con respecto a la taxonomía que distingue a las series asociadas a contenidos no verosímiles o fantásticos, lo que se ha ubicado tradicionalmente dentro de la ciencia ficción, el terror y la fantasía. Las distinciones entre las tres formas genéricas básicas han resultado históricamente un tanto ambiguas y contradictorias en los textos reales encontrados en la literatura y el cine. Algunos ejemplos clásicos como el Poema de Gigamesh (2500-2000 a.C.) o la Odisea (S. VIII a.C) incluyen descubrimientos, avances científicos en mundos de mitos y magia, de forma que la ciencia de hoy es la magia del ayer, mientras que la magia de hoy se convierte en la ciencia del mañana (Johnson-Smith, 2005: 17). Ya lo auguraba el escritor Arthur C. Clarke en Perfiles del futuro (1973) con su tercera ley científica afirmando que «Toda tecnología lo suficientemente avanzada es indistinguible de la magia».

Más que en ningún otro campo, en la práctica de la ficción televisiva las delimitaciones entre esos géneros en los que tienen cabida espacios, personajes o eventos imposibles se vuelven confusas, ensayando con las distintas opciones dentro de una misma propuesta y mezclándose con otras fórmulas y contenidos propios de la ficción verosímil. Si la flexibilidad del género siempre había sido una posibilidad abierta en el medio, la llegada de la era hipertelevisiva y el consecuente incremento de producciones ha supuesto el máximo exponente de experimentación, planteando la necesidad de replantear las definiciones tradicionales. Este fenómeno se ha convertido en una máxima en la construcción narrativa de las ficciones televisivas, dificultando la separación real entre géneros en numerosas propuestas seriales, ya no solo dentro de las formas genéricas extraordinarias sino también con otros géneros realistas.

Con el fin de evitar los restrictivos márgenes de los vocablos genéricos heredados de otros medios, se engloba cada una de sus formas dentro de una gran superestructura: el macrogénero de lo extraordinario ${ }^{1}$. El término macrogénero acoge multitud de propuestas heterogéneas, unidas por la aparición de lo increíble o imposible en el mundo natural. En este artículo se emplea el concepto extraordinario para definir aquellas propuestas que ofrecen una representación de una realidad, o de aspectos incluidos en la misma, tales como personajes, espacios, objetos o eventos, imposibles o todavía ajenos a nuestra experiencia empírica, en nuestro mundo, o en otros, donde rigen diferentes leyes físicas, o incluso, sobrenaturales o mágicas. El punto de partida que se ha decidido adoptar es la concepción dual que Javier Rodríguez Pequeño propone en Géneros literarios y mundos posibles (2008) entre el macromodelo del mundo real, que en el presente trabajo serían las ficciones ordinarias o de lo ordinario, y el macromodelo del mundo fantástico, llamadas aquí las ficciones extraordinarios o de lo extraordinario. El primero se corresponde con las ficciones realistas que reproducen la experiencia de vivir en un mundo que reconocemos como nuestro mientras que el segundo supone la transgresión del mundo real objetivo en cualquiera de sus formas, sin que sea realmente relevante el origen, mágico o tecnológico, de esa ruptura de la norma.

\section{La hibridación de géneros en la hipertelevisión}

En lo que respecta a la segmentación histórica del discurso televisivo, algunos investigadores en comunicación (Casetti y Odin, 1990; Eco, 1999) han señalado tradicionalmente dos etapas cronológicas iniciales del medio, la paleotelevisión y la neotelevisión, a las que posteriormente se añade una tercera fase, la hipertelevisión (Scolari, 2008; Gordillo, 2009), contextualizada en el nuevo milenio. En el periodo paleotelevisivo se produce la conformación de los géneros televisivos, basada en la distinción tradicional entre los dos macrogéneros, el informativo y el entretenimiento, que estaban fuertemente codificados y separados entre sí para ser perfectamente diferenciados por el público.

Durante la era neotelevisiva, por la serie de transformaciones descritas previamente, comienza la crisis de género y formato, que deriva en el desdibujamiento de los límites y en la progresiva tendencia a que la parrilla se construya de forma heterogénea. Esta alteración de los patrones dificulta la clasificación de las propuestas, siendo una inclinación que se amplificará enormemente durante la era hipertelevisiva, ya que en esta última etapa se produce la adhesión de programas a varios géneros y la creación de formatos novedosos a medio camino entre la información y el entretenimiento. Aunque los orígenes de este tipo de fusiones entre programas televisivos se remontan a la primera edad televisiva, pues el medio por sí mismo tiene un carácter híbrido, es ahora cuando han empezado a tener un rol relevante en las construcciones narrativas, empleándose de forma consciente e incluso como estilema estético.

De esta forma, el género en televisión ha pasado de estar dividido en categorías tradicionales a una crisis del propio concepto, cuya pureza prácticamente ha desaparecido en la práctica; se habla así de cómo en «la televisión hipermoderna», descrita por García de Castro, «los géneros se han disuelto para dar paso a la hibridación» (2007). La causa principal que motiva la mezcla de géneros en televisión es económica, pues supone la ampliación del mercado (Fiske, 2006; Nelson, 2008; Shimpach, 2010) a través de la adhesión de audiencias colaterales pertenecientes a otros espacios geográficos e inscritas en diversos rangos de edad.

\footnotetext{
1 Entre las distintas acepciones que definen el término extraordinario ${ }^{1}$ (RAE en su 22. a edición versión electrónica), procedente del vocablo latino extraordinarius, se encuentra como primera definición su uso como adjetivo cuyo significado es "fuera del orden o regla natural o común", lo que engloba perfectamente el corpus de series que van a ser analizadas en el presente trabajo. Disponible en http://lema.rae.es/drae/?val=extraordinario (Consultado el 10-12-2014).
} 
La tendencia a la hibridación o la mezcla de géneros se acrecienta en el nuevo milenio, afectando a todos los programas y produciéndose una retroalimentación entre géneros y formatos, influyendo también en la pureza de los grandes géneros de información y entretenimiento. Se afirma incluso que la televisión ha olvidado su función social y cultural reduciendo cualquier formato a la espectacularización y, por tanto, al entretenimiento (Ribés, 2005) en cualquier forma de comunicación que se adopte. En relación al mestizaje entre ficción y no ficción, Gordillo afirma que «si los discursos de la realidad se ficcionalizan y espectacularizan, la ficción va a sufrir una metamorfosis influida por los discursos informativos» (2009: 38), de manera que la realidad a veces parece poco natural y la ficción más verosímil. Así el reality show se construye con una estructura narrativa cercana a la de los relatos de ficción, se consolidan formatos mixtos como el docudrama y se afianzan géneros jóvenes como el falso documental. La noción de los límites precisos se deja llevar por la lógica contradictoria en una especie de pastiche en el que se crean espacios intermedios a medio camino entre la ficción y la realidad. Imbert considera que actualmente nos movemos en el terreno de la transterritorialidad y el espacio "entre-deux», que define esa inclinación que tiene la hipertelevisión «a jugar con los límites en su representación de la realidad y a la tendencia a crear espacios intermedios, intersticiales, que se sitúan en las fronteras de géneros y categorías, en un espacio ambivalente» (2008: 61).

La dependencia existente entre géneros, formatos y tópicos se ha vuelto muy flexible en las narrativas del siglo XXI, donde el préstamo y el cruce de fórmulas y estructuras es la base en la construcción de muchas ficciones. La hibridación de géneros en las series no es pues la degradación involuntaria de los géneros, sino que es la consecuencia de un proceso evolutivo, pudiendo analizarse incluso como un criterio de calidad (Pujadas, 2011: 194). Así, las series son productos mestizos que se mezclan y combinan con formulas tradicionales precedentes, empleando una narrativa serializada sofisticada y cultivando una mitología interna compleja (Thompson, 2007: XIX), en donde tienen cabida tanto un western espacial como una soap opera noir o un drama construido desde la comedia. Cualquier mestizaje es posible dentro de la ficción siempre que se respete la madurez del espectador, cuyo vasto conocimiento lo ha convertido un agente comunicativo exigente que requiere coherencia narrativa en sus series favoritas.

\section{Los dramáticos en el nuevo milenio}

La presente investigación, centrada en procesos de hibridación de géneros, se acota en principio mediante la elección de dos variables: la primera, la delimitación espacio temporal, ciñéndose a la ficción producida en Estados Unidos durante las primeras décadas del siglo XXI; la delimitación geográfica se explica por la increíble repercusión que la producción norteamericana tiene en el mundo, siendo el mayor país exportador de televisión y cine, definiendo además el discurso de calidad televisiva en el panorama internacional (Pujadas, 2011: 231). En segundo lugar, se circunscribe únicamente al formato dramático, que ha conseguido un gran protagonismo dentro de la ficción reciente, tanto a nivel de crítica como de público, inaugurando una nueva edad dorada del medio. Históricamente, el estudio de los dramas televisivos, al que también se le llama dramático, drama o teleserie, se ha observado como complemento dentro de los estudios fílmicos, en gran medida porque son considerados diversiones efímeras (Nelson, 2008: 14), pero su integración en el ocio y en la cultura contemporánea motivan estudios más exhaustivos en los que el formato no sea examinado como un apéndice de otro medio.

Rescatando la definición de Gordillo (2009: 106), las series dramáticas o de acción duran aproximadamente 45 minutos, sus estructuras narrativas pueden combinar lo serial con lo episódico y abarcan gran cantidad de temas, desde la aventura a la ciencia ficción. No obstante, se debe señalar que los formatos también están sufriendo un proceso evolutivo, surgiendo nuevas fórmulas híbridas a medio camino entre distintas estructuras. Es muy interesante la aparición, dentro de los dramáticos, de la "serie limitada»", fusión resultante entre este formato y la miniserie, cuyo parecido más cercano se establece con las "Limited Series" de los cómics, que son historias autoconclusivas paralelas a las grandes colecciones con una duración limitada y con carácter de exclusividad. En la televisión del siglo XXI, las series limitadas se dividen en dos grupos: por un lado, aparecen las series limitadas como antologías, compuestas por distintas temporadas pero cada una de ellas cerrada con una trama autoconclusiva y protagonizada por personajes diferentes. Por otro lado, las series limitadas revival, que desde el punto de vista narrativo son continuaciones o nuevas entregas, pero se presentan como «eventos televisivos», que pueden concluirse en una sola temporada o, por el contrario, continuar, pero que no nacen en principio con intención de prolongarse en el tiempo.

La televisión se encuentra actualmente en un periodo de transición acuciante (Shimpach, 2010) que está afectando tanto a la producción como a la recepción, pues la televisión se está reorganizando como industria y se está adaptando a las necesidades de un público segmentado y más exigente, lo que sin duda marca la creación de la ficción serial. Con la entrada del siglo XXI, concretamente fechada por algunos autores en 1999, se data el comienzo de una «Nueva etapa del drama televisivo o era del drama» en los Estados Unidos, expresiones parejas acuñadas por James L. Longworth Jr. (2002) para describir el gran momento que vive la ficción norteamericana desde el final del siglo XX y el inicio del nuevo milenio.

Se asocia esta corriente productiva a un intenso momento de actividad industrial pero también artística, considerándose incluso que las series se han convertido en una auténtica vanguardia creativa (García de Castro, 2007). Carrión comenta este excepcional momento histórico con la siguiente aseveración: «Las teleseries norteamericanas han ocupado, durante la primera década del siglo XXI, el espacio de representación, que durante la segunda mitad del XX fue monopolizado por el cine de Hollywood» (2011: 13). Para afianzar esta asociación de ideas, se ha producido también una migración de talentos del medio cinematográfico al televisivo, pues actores consagrados protagonizan series obteniendo gran reconocimiento artístico -entre ellos Glenn Close, Kevin Spacey, Jeff Daniels, Jessica Lange- y otros nombres vinculados al cine se han pasado a la producción -Tom Hanks, Steven Spielberg, Martin Scorsese, Jerry Bruckheimer, etc. Esta comparativa entre los dos medios audiovisuales hegemónicos se ha vuelto bastante común, de manera que las series televisivas adquieren un matiz de calidad simplemente por ser relacionadas con las producciones cinematográficas clásicas. Rincón (2013: 168) explica esta situación de forma bastante elocuente, denunciando ese tipo de discurso que separa ilusoriamente entre alta y baja cultura: «cuando una película es mala, se dice que es televisiva: y cuando un autor quiere exhibirse en televisión dicen que la obra está hecha en estilo

\footnotetext{
2 Desde 2015 los premios Emmy han transformado el nombre de la categoría, motivado sin duda por la creciente importancia de este nuevo formato. Véase la nota de prensa de los premios de la $67^{\text {th }}$ EMMY AWARDS NOMINATIONS en donde se especifica que "The Outstanding Miniseries category was redefined this year as Outstanding Limited Series". Disponible en http://www.emmys.com/sites/default/files/Downloads/67th-nominations-list-v1.pdf (Consultado el 16-7-2015).
} 
cinematográfico».

Técnicamente, esta etapa está caracterizada por la proliferación de series de gran calidad, cuya distribución se diversifica enormemente, gracias a la coexistencia del cable, el satélite y las nuevas tecnologías, señalando en este último caso la reciente incorporación de nuevas formas de distribución de dramáticos en Internet, que compiten directamente con los canales tradicionales y que se constituyen como una vía alternativa para el desarrollo de la ficción de calidad. Estas plataformas de distribución también se han lanzado en la producción de dramáticos, como es el caso de Netflix o Amazon. Se resalta de nuevo que vivimos en la era de la convergencia cultural (Jenkins, 2006), donde los medios tradicionales y los nuevos conviven con clásicas y experimentales formas de distribución, en un singular clima de cooperación y competencia entre los grandes conglomerados mediáticos.

Pero sin duda lo que más ha cambiado en la televisión es la especialización narrativa y temática. Los Soprano (The Sopranos, HBO: 19992007) es la serie que sirve de bisagra entre la anterior etapa y la nueva era, pues pone de manifiesto que otra televisión de calidad es posible, llegando a denominarse a esta era de producción la «Post-Soprano age» (McCabe y Akass, 2007: 11). Las series de esta época se presentan como ofertas competitivas, de elevado riesgo temático y técnico, que llevan al extremo la hibridación de géneros y formatos como fórmula habitual. La calidad y el éxito popular se han vuelto completamente compatibles, mientras que el espectador ha desarrollado un alto grado de madurez que le hace más selecto a la hora de elegir sus productos.

Por último, la figura del showrunner se consagra, convirtiéndose en la figura más importante en el conglomerado creativo e industrial de la televisión norteamericana. Nombres propios como Alan Ball, David Chase, David Simon o Shonda Rhimes, comienzan a ser respetados como creadores y la noción de autoría cada vez está cada vez más presente en el marco televisivo.

\section{Las series extraordinarias en el nuevo ecosistema mediático}

Esta breve reflexión sobre el panorama de producción reciente sirve para entender mejor el contexto que origina el gran incremento de series extraordinarias desarrolladas durante el nuevo milenio. Hermida (2010: 211) comenta que «el universo de lo mágico y lo sobrenatural se asienta en la programación televisiva» en la actualidad, asociando este auge al atractivo de lo rupturista en tiempos de crisis, cuando desaparece la necesidad de explicaciones y justificaciones racionales, que son sustituidas por ficciones especulativas 0 metafóricas.

Otras razones pueden añadirse al éxito del género en televisión a partir del siglo XXI: por un lado, tal y como se ha expuesto previamente, el aumento de la atención mediática sobre el showrunner televisivo como figura relevante del panorama artístico también influye en el desarrollo del macrogénero, consagrándose autores especialistas en lo extraordinario como Joss Whedon, J.J Abrams, Roberto Orci, Alex Kurtzman, Tim Minear o Jane Espenson; ante las amplias posibilidades que ofrecen las narrativas extraordinarias, estos creadores experimentan dentro de sus obras con el vasto abanico de posibilidades, sin tener que regirse por leyes físicas o relaciones lógicas de causa/consecuencia que sí rigen los mundos ordinarios.

Por otro lado, el desarrollo en el siglo XXI de la cultura fan y del macrogénero extraordinario está estrechamente ligado, siendo ambos conceptos completamente dependientes entre sí. Se ha modificado la relación con la audiencia, más joven y fragmentada que nunca, de manera que los receptores han dejado de verse como simples agentes pasivos, transformándose en una parte dinámica del acto comunicativo, hasta el extremo de que investigadores como Fiske rechazan el término «audiencia» y prefieren otros conceptos como «lectores» o «videntes» por tener una connotación mucho más enérgica (2006, 17). Los consumidores se han convertido en «prosumidores», es decir, usuarios activos que no sólo consumen sino crean, producen y comparten contenidos y recursos (Maguregui, 2010). Dentro de este grupo, los más entregados y los que mayor vinculación sienten con el producto son los fans, que se han trasladado de los márgenes invisibles de la cultura popular al centro neurológico de la producción y el consumo (Jenkins, 2006: 12). Las narrativas extraordinarias tienen un potencial especial para expandirse, ya sea de forma canónica desde el propio aparato de producción, o mediante la intervención activa del público a través de trabajos amateur en los que prologan o versionan sus historias favoritas. El terreno de lo extraordinario favorece la creación de contenidos generados por los usuarios y su inmersión activa en un universo inventado, afirmándose incluso que la cultura fan pertenece a los géneros fantásticos, estrechamente vinculada a la ciencia ficción, la fantasía y el terror (Hills, 2004: 510).

La estética del espectáculo (Darley, 2000; Isaacs, 2008), propia de la contemporaneidad más reciente y primordial para la definición de las formas modernas de entretenimiento popular, encuentra en las narrativas extraordinarias un espacio ideal para mostrar los avances en el tratamiento de la imagen de los últimos años, de modo que en ocasiones la tecnología es en sí misma el mensaje (Darley, 2000: 53). Además del relato, la propia forma de presentarlo obtiene el mismo interés, inscribiéndose en el fenómeno «televisuality» (Caldwell, 1995), que define ese tipo de producciones caracterizadas por su estilización y exhibicionismo visual a través de efectos especiales y cuidado técnico de la imagen. De este modo, el espectador es testigo de construcciones espaciales colosales, seres sobrenaturales, hechizos mágicos y escenas de acción que definen el universo representado tanto como la propia historia.

No obstante, paradójicamente también se está produciendo el efecto contrario en la producción actual, utilizándose el elemento extraordinario de manera velada o casi imperceptible en algunas series de la era hipertelevisiva, cuidando el mensaje humano por encima de lo demás, empleando lo imposible como excusa para crear espacios de catarsis y minimizando el uso de efectos especiales. Estas dos tendencias tan divergentes conviven en un espacio catódico amplio, en el que existe una importante demanda de productos extraordinarios por parte de diversos sectores de la audiencia con inquietudes completamente diferentes.

En definitiva, las series extraordinarias de la era hipertelevisiva conforman el objeto de estudio ideal para observar procesos de hibridación por la extrema flexibilidad de su forma y su contenido, propiciando muchos de los discursos televisivos más interesantes de los últimos dieciséis años. 


\section{Metodología}

El fundamento de este estudio es la verificación de los procesos de hibridación genérica en el formato dramático de contenido extraordinario que se están produciendo durante la era hipertelevisiva, centrando más la atención en cómo se producen esos mestizajes discursivos que en sus causas. La investigación se focaliza especialmente en el ámbito del propio mensaje, siguiendo la vía del estudio analítico de los programas de televisión como textos (Abercrombie, 1996; Bignell, 2005), por lo que nos situamos dentro del paradigma cualitativo del análisis textual, empleando metodologías propias del análisis narrativo y de la semiótica. Partiendo de esta base se imponen dos objetivos principales:

1. Entender qué elementos genéricos construyen una serie de contenido extraordinario en la era hipertelevisiva, y la mayor 0 menor importancia narrativa que adquieren dichos elementos dentro de un texto determinado

2. Observar en qué magnitud se fusionan los elementos de lo extraordinario con otros componentes propios de otros géneros e incluso característicos de otros formatos.

En lo que respecta a los casos de estudio, teniendo en cuenta que actualmente las temáticas de lo extraordinario atraviesan por un momento de auge, completando una significativa transición de la discreción al fenómeno de masas (Hermida, 2010: 224) y que eso se refleja en el inmenso volumen de series susceptibles de analizarse, se han escogido tres textos muy representativos dentro del ecosistema mediático actual: Galáctica: estrella de combate (Battlestar Galactica, SyFy: 2004-2009), Juego de Tronos (Game of Thrones, HBO: 2011-) y American Horror Story (FX: 2011-). Los tres casos de estudio cumplen las siguientes premisas:

1. Cada una de las series representa un ejemplo paradigmático de una fórmula genérica extraordinaria concreta dentro de la producción global de la era hipertelevisiva.

Galáctica: estrella de combate es la que más se vincula en primera instancia al concepto de ciencia ficción clásica, pues narra cómo una gran nave militar, liderada por el Capitán Adama, trata de mantener a salvo en un convoy espacial a la humanidad que ha quedado tras el demoledor ataque de los robots cylon (creados por la propia humanidad).

Por su parte, Juego de Tronos se contextualiza en un universo imaginario asociado a la fantasía medieval, centrándose en los continuos enfrentamientos entre las distintas familias de Poniente por el Trono de Hierro, especialmente entre los Lannister, y los Stark, antiguos reyes del Norte, apoyados o traicionados por el resto de Casas de Poniente; mientras tanto, al otro lado del Mar Angosto una joven heredera desterrada, Daenerys Targaryen, se prepara para volver a reclamar el reino.

Por último, de las propuestas analizadas, American Horror Story es la que más se centra en los motivos temáticos del terror, pues se rescatan espacios habituales asociados tradicionalmente al género -casa encantada, psiquiátrico, aquelarre, circo de fenómenos, hotel embrujado- y se pueblan dichos lugares de personajes vinculados al género -fantasmas, maniacos homicidas, extraterrestres, brujas, personas con poderes, payasos psicóticos, ángeles, demonios y vampiros. Al tener carácter antológico, cada temporada tiene un argumento distinto, lo que se suscribe con un subtítulo diferente: Murder House, Asylum, Coven, Freak Show y Hotel.

2. Las propuestas poseen cualidades, textuales o extratextuales, que las hacen relevantes en su contexto televisivo.

Galáctica: Estrella de Combate, reinventa las posibilidades de la ciencia ficción a la vez que re-imagina un universo previo, pues la producción es una nueva versión para la productora Universal Pictures de la serie previa de Glen A. Larson Galactica. Estrella de combate (Battlestar Galactica, Sci-Fi, 1978-1979), que ya en su momento observó el potencial expansivo de este mundo, desarrollando una secuela de diez episodios llamada Galactica 1980 (ABC: 1980) e incluso un nuevo intento fallido de teleserie que nunca llegó a realizarse llamado Galactica: The Second Coming. A nivel temático, la ficción se construye a través de múltiples tramas alegóricas cuya finalidad es el planteamiento de continuos conflictos éticos, tratándose temas como «el aborto, derechos de los prisioneros, derechos de los trabajadores y derechos sindicales, división racial, atentados terroristas, prostitución, drogas, fraude electoral, economía sumergida o el genocidio» (Benchichà, 2015: 235).

La gran repercusión mediática mundial de Juego de Tronos pone en evidencia el éxito internacional que pueden alcanzar determinadas producciones de fantasía medieval, lo que ya demostró el estreno cinematográfico de El señor de los anillos: la Comunidad del Anillo (The Lord of the Rings: The Fellowshipof the Ring, 2001) a principios de milenio. Se afirma incluso que mientras Tolkien es el «creador del género épico fantástico» con la creación de la mítica saga, Martin es «el autor que dotó de madurez a este tipo de ficción» (Miller, 2012: 14). El relato destaca por la importancia de los conflictos dramáticos así como por la amplia y detallista mitología que conforma el universo desarrollado.

American Horror Story juega con el concepto de formato, pues mezcla cualidades de la antología, el dramático y la miniserie, ejemplificando a la perfección el nuevo modelo de serie limitada, lo que además hace empleando a la mayor parte del elenco artístico en cada una de las temporadas pero ubicados en distintos escenarios e historias con personajes diferentes. Su éxito ha repercutido en la creación de otros productos de terror, género bastante ausente en la ficción serial reciente, como Scream (MTV: 2015-) o Scream Queen (Fox: 2015-).

3. Las series son producciones, o en su defecto coproducciones, estadounidenses que han sido distribuidas durante el nuevo milenio nacional e internacionalmente, y que además pertenecen a distintos canales televisivos.

Galáctica: Estrella de Combate, creada por Ronald D. Moore para el canal temático especialista en ciencia ficción Sci Fi, consta de cuatro temporadas emitidas entre 2004 y 2009, aunque fue lanzada con una miniserie previa (2003) que funciona como capítulo piloto. Tras su emisión se consideró que la ficción no cumplía la cuota de público para convertirse en una serie regular, por lo que su continuación parecía poco probable; no obstante, Sci Fi firmó un acuerdo con el canal británico Sky 1 que se comprometió a cofinanciar la primera temporada a 
Juego de Tronos, perteneciente al canal estadounidense de pago premimum HBO y creada por David Benioff y D. B. Weiss, es una adaptación de la saga fantástica Canción de Hielo y Fuego del escritor George R. R. Martin, que todavía hoy permanece inacabada y cuyo último volumen publicado es Danza de Dragones (2012), a la espera de que se edite la sexta entrega, Vientos de invierno. Actualmente la serie está conformada por seis temporadas que ya han adelantado los sucesos acontecidos en la última de las novelas publicadas.

El último caso, American Horror Story, es una apuesta arriesgada, porque además de desarrollar contenido de terror, se caracteriza por su alto contenido violento y sexual, lo que sólo puede concebirse dentro de un canal como FX, destinado a un público adulto mayormente masculino. La ficción, creada por Ryan Murphy y Brad Falchuk, consta actualmente de cinco temporadas, aunque ya se ha anunciado que existirá una sexta entrega.

\section{Resultados}

\subsection{Galáctica: Estrella de Combate: la ciencia ficción mitológica y naturalista}

A pesar de desarrollarse en el espacio e incluir la existencia de seres extraordinarios mecánicos creados a imagen y semejanza del hombre, la serie se define como ciencia ficción de manera secundaria, resaltando en gran medida la presencia de tramas corales que incluyen acción, aventura, drama o mitología fantástica. Las dos primeras etiquetas vienen motivadas por la continua guerra entre humanos y cylon, visualizada a través de combates espaciales así como la persistente búsqueda de recursos vitales y objetos mitológicos que marcan el avance de la trama. No obstante, la mayor parte de la historia se fundamenta en los problemas consecuentes de la reconstrucción de la civilización, conflictos éticos, políticos y de liderazgo, siendo posible relacionar la mayor parte de los dilemas con los que existen en el contexto real, a modo de metáfora. La entrada de la fantasía entronca con la religión y la mitología, pues después de todo, es la historia de un peregrinaje hacia una tierra prometida.

Aunque las naves, el espacio y los robots son motivos asociados a la ciencia ficción, se observa como la puesta en escena se cimenta en la exhibición de un realismo sucio, naturalista y aparentemente testimonial, que va en contra de la iconografía habitual del género, huyendo de los colores brillantes y el antinaturalismo propio de universos como el de Star Trek o Star Wars. Ese falso aspecto realista consigue que los elementos extraordinarios resulten todavía más sorprendentes. El hecho de que la aparición de lo extraordinario esté más vinculado a los contenidos míticos y religiosos que a los elementos de ciencia ficción, exhibidos de forma realista y carente de espectacularidad, es muy significativo a nivel genérico, pues se apuesta por una ciencia ficción mitológica, cercana a la fantasía, con una intención incluso documental apoyada por una representación audiovisual carente de artificios.

La mezcla de referentes hace patente que la construcción de Galáctica parte de una base compleja en donde lo ordinario y lo extraordinario tienen la misma cabida sin que sean elementos contradictorios en un discurso marcado por la horizontalidad. El resultado es un texto construido a base de múltiples capas consecuente de un gran bagaje cultural pero sin intención de autoconciencia o referencialidad explícita.

\subsection{Juego de Tronos: la fantasía cercana a la representación histórica}

Aunque se inscriba a menudo dentro de la aventura y la fantasía, Juego de Tronos es sobre todo un drama de personajes cuyas tragedias marcan la evolución de la historia. La fragmentación serial de las tramas corales aumenta la tensión provocada por los conflictos dramáticos, pues la sensación de realismo aumenta al no resolverse estos inmediatamente y la ausencia de componente episódico otorga una sensación de extrema continuidad.

En este mundo tienen lugar determinados eventos extraordinarios que nunca llegan a robar el protagonismo a las tramas políticas y humanas, de manera que lo ordinario (muertes, alianzas, traiciones) siempre es el auténtico motor del relato y lo que acaba marcando el devenir de la historia. La serie busca siempre la verosimilitud, apoyándose en lugares y hechos que recuerdan a nuestro pasado histórico (vinculación de Invernalia al Medievo o de Dorne al Califato de Córdoba), pareciendo más una ficción verídica que una narración extraordinaria.

Centrándonos exclusivamente en el componente extraordinario, Juego de Tronos hace que la fantasía sea sorprendente dentro del discurso, de forma que, por ejemplo, el nacimiento de los dragones al final de la primera temporada es un hecho desconcertante y fascinante tanto para el espectador como para los propios habitantes del relato. Si bien es un universo inventado, lo ordinario rige más la vida de sus habitantes que lo extraordinario, que consideran la magia propia de leyendas y de civilizaciones ancestrales, aunque si bien es cierto que a medida que avanza el relato a través de las temporadas, lo mágico va tomando cada vez más terreno.

No obstante, la serie parte de las convenciones propias del género fantástico para jugar con las expectativas del espectador. La inexistencia de un protagonista heroico claro, o mejor dicho, la posible muerte de los que se presentan como tales (Eddar y Robb Stark, Jon Nieve, líderes de la casa Stark) por ser los epítomes de la honorabilidad y la justicia, produce un alejamiento de las reglas de la fantasía y la épica, porque también distancia la posibilidad de un final feliz y el triunfo del bien sobre el mal, que suele ser una condición básica de la literatura taumatúrgica (Rodríguez Pequeño, 2008: 180).

Otros personajes tienen conexiones puras con la tradición de la fantasía. Entre ellos, Daenerys Targaryen se presenta desde el propio final de la primera temporada como el auténtico rol superheroico, siendo el gran vínculo con el género, impermeable en gran medida a las calamidades que afectan el transcurso de las vidas del resto de personajes de Poniente. El personaje vive su viaje mítico particular, con las

${ }^{3}$ La serie debutó en Sky 1 en Octobre de 2004 y en Sci Fi en enero de 2005. 
pruebas y sacrificios exigibles al auténtico héroe para comprobar su derecho al Trono de Hierro. Sin embargo, los puntos de giro tan sorpresivos que se producen en la serie pueden truncar las expectativas del viaje del héroe.

\subsection{American Horror Story: el pastiche extraordinario como género}

Aunque el propio título haga referencia al terror, American Horror Story se plantea desde la propia concepción como un cajón de sastre, donde tiene cabida también el drama, el thriller, o incluso el musical, dando como resultado un pastiche de motivos extraordinarios y ordinarios, en una mezcla heterogénea e incluso bizarra. En ocasiones el efecto de terror se vuelve incluso cómico por su uso hiperbólico, pues no podemos olvidar que el pastiche funciona como una parodia vacía (Jameson, 1991: 44), que es precisamente lo que sucede con esta serie.

La combinación de temas asociados a distintos géneros impide la asociación con una categoría determinada, y el uso de referentes temáticos vinculados a la historia del terror tiene más sentido como homenaje que como actualización de lugares comunes, de ahí que sea una de las series referenciales más interesantes de los últimos años. Se reinterpretan tópicos argumentales muy conocidos: una casa encantada en la actualidad poblada por fantasmas, escenario utilizado en películas tan emblemáticas como Poltergeist: fenómenos extraños (Poltergeist, 1982) o Bitelchus (1988); un psiquiátrico en el que se realizan atrocidades y que también es escenario de eventos sobrenaturales, que recuerda a otros temibles centros de recuperación mental como los vistos en Shutter Island (2010) o Sucker Punch (2011); un aquelarre de brujas en el sur de Estados Unidos, sin duda deudor de Las brujas de Eastwick (The Witches of Eastwick, 1987); un circo ambulante donde conviven extraños seres humanos, claro homenaje al clásico La parada de los monstruos (Freaks, 1932); por último, el gran hotel diabólico, que rememora el clásico de terror El resplandor (The Shining, 1980).

La serie rescata tópicos del terror pero la falta de protagonismo de todos ellos y su superposición desemboca en un collage. Partiendo de una serie ya de por sí visiblemente híbrida en la concepción de lo extraordinario, se atreve incluso con la introducción de secuencias musicales a partir de la segunda temporada que desafían todavía más las expectativas del espectador, rompiendo por completo la atmósfera decadente y asfixiante, creando paréntesis casi cómicos dentro de la trama.

La estructura narrativa serial, caracterizada por la carencia de arquetipos fiables y estables y por la ausencia de un destino argumental, no es afín a las arquitecturas genéricas tradicionales, de manera que la conclusión del relato es impredecible en cada una de las temporadas, pudiendo morir los protagonistas en cualquier momento. La estética se convierte en el agente homogeneizador de la serie sobre el contenido, de lo que se infiere que el género es más perceptible por su peculiar representación audiovisual que por la propia sintaxis que configura el texto, una característica que definirá todas las temporadas, sea cual sea el tema desarrollado.

\section{Conclusiones}

En las series analizadas, la hibridación es el resultado de una serie de elecciones, temáticas y estructurales, que diseñan el resultado final y que se sintetizan en tres aspectos principales:

1. La construcción serial de las tres propuestas analizadas demuestra como la horizontalidad se ha convertido en un valor en alza, prescindiendo prácticamente del elemento episódico, tan presente en las producciones televisivas extraordinarias de épocas precedentes. Esta elección conlleva dos consecuencias: la dilatación temporal en la resolución de conflictos dramáticos y el aumento de la verosimilitud por esa imposibilidad de arreglarlos rápidamente, pues la magia y la tecnología tienen sus límites.

2. El principio de coralidad absoluta que rige las tres series desafía las expectativas genéricas por la necesidad referida de reconfigurar continuamente la posición de los personajes desde una perspectiva funcional, lo que duda influye también en la observación de los personajes como héroes. Por el contrario, en los géneros fuertemente codificados, es muy importante el punto de llegada estimado del relato, es decir, la previsión del posible final en relación al supuesto de partida.

3. La representación audiovisual de contenidos extraordinarios apuesta por un acercamiento realista y naturalista, que incluso afea los universos plasmados, de forma que la verosimilitud, además de construirse narrativamente, se consigue mediante elecciones estéticas.

En definitiva, el análisis de los casos ha puesto en evidencia que la construcción narrativa de estas series se caracteriza por su compleja y heterogénea mezcla genérica.

\section{Bibliografía}

Abercrombie, N. (1996). Television and Society. Cambridge: Polity Press.

Benchichá López, N. Y. (2015). La tercera edad dorada de la televisión. Battlestar Galactica y las nuevas formas de pensar, hacer y consumir el drama televisivo norteamericano (Tesis doctoral). Recuperado de: http://www.tesisenred.net/handle/10803/285053

Bignell, J. (2005). An introduction to Television Studies. New York: Routledge.

Caldwell, J. T. (1995). Televisuality. Style, Crisis and Authority in American Television. New Brunswick: Rutgers University Press.

Carrión, J. (2011). Teleshakespeare. Madrid: Errata Naturae.

Casetti, F. y R. Odin, (1990). De la paléo- à la néo-télévision. Communications. Télévisions/mutations (51), 9-26.

Eco, U. (1999). La transparencia perdida. Barcelona: Lumen. 
Fiske, J. (2006). Television culture. London: Routledge.

García De Castro, M. (2007). La televisión hipermoderna. Telos: Cuadernos de Comunicación, Tecnología y Sociedad, (73). Recuperado de http://sociedadinformacion.fundacion.telefonica.com/telos/articulotribuna.asp@idarticulo=2\&rev=73.htm

Gordillo, I. (2009). La hipertelevisión: géneros y formatos. Ecuador: Ciespal.

Hermida, A. (2010). La omnipresencia de lo sobrenatural. Representaciones del no-cuerpo en las series de ficción televisiva. En Guarinos, V. e I. Gordillo (eds.). Todos los cuerpos. El cuerpo en televisión como obsesión hipermoderna (pp. 209-226). Córdoba (Argentina): Babel Editorial.

Hills, M. (2004). Defining Cult Tv. Texts, Inter-Texts and Fan Audiences. En Allen, R. C. y A. Hill (eds.). The Television Studies Reader (pp. 509-524). London: Routledge.

Imbert, G. (2008). El transformismo televisivo. Postelevisión e imaginarios sociales. Madrid: Cátedra.

Isaacs, B. (2008). Toward a New Film Aesthetic. New York \& London: Continuum.

Jameson, F. (1991). El posmodernismo o la lógica cultural del capitalismo avanzado. Barcelona: Paidós.

Jenkins, H. (2006). Convergence Culture. Where Old and New Media Collide. New York: New York University Press.

Johnson-Smith, J. (2005). American Science Fiction TV. Star Trek, Stargate and Beyond. London: I. B. Tauris.

Jowett, L. (2009). Plastic Fantastic? Genre and Science/Technology/Magic in Angel. En Geraghty, L. (ed.). Channeling the Future. Essays on Science Fiction and Fantasy Television (pp.167-182). Lanham, Toronto y Plymouth, Scarecrow Press.

Longworth, J. L. (2002). Tv creators: Conversations with America's Top Producers of Television Drama, Volumen 2. Syracuse: University of Syracuse Press.

Maguregui, C. (2010). Narrativas transmedia y cruce de plataformas en Lost, en Textodromo [texto previo de Julio 2009, Buenos Aires]. Recuperado de http://textodromo.files.wordpress.com/2009/08/lostmaguregui.pdf

Mittell, J. (2004). Genre and Television. From Cop Shows to Cartoons in American Culture. New York: Routledge.

Nelson, R. (2008). Studying Television Drama. En Creeber, G. (ed.). The Televisión Genre Book (pp. 14-15). London: British Film Institute.

Pujadas, E. (2011). La televisión de calidad. Contenidos y debates. Bellatera, Barcelona, Castellón de la Plana y Valencia: Aldea Global.

Ribés Alegría, M. (2005). La hibridación de géneros y la crisis de la calidad televisiva: consejos audiovisuales en el panorama televisivo. Comunicar: Revista científica iberoamericana de comunicación y educación, (25). Recuperado de http://www.revistacomunicar.com/verpdf.php?numero=25\&articulo=25-2005-131

Rincon, O. (2013). Los formatos audiovisuales de la identidad. En Guarinos, V. y A. Sedeño (eds.). Narrativas audiovisuales digitales. Convergencia de medios, multiculturalidad y transmedia (pp. 165-192). Madrid: Fragua.

Rodríguez Pequeño, J. (2008). Géneros literarios y mundos posibles. Madrid: Editorial Eneida.

Scolari, C. (2008). Hacia la hipertelevisión. Los primeros síntomas de una nueva configuración del dispositivo televisivo. Diálogos de la Comunicación, (77). Recuperado de http://www.dialogosfelafacs.net/77/articulos/pdf/77CarlosScolari.pdf

Shimpach, S. (2010). Television in transition. The Life and Afterlife of the Narrative Action Hero. United Kingdom: Wiley-Blackwell.

Thompson, R. J. (2007). Preface. En McCabe, J., y K. Akass (eds.), Quality Television. Contemporary American Television and Beyond (pp. XVII-XX). London \& New York: I. B. Tauris.

Tous, A. (2010). La era del drama en televisión. Perdidos, CSI: Las Vegas, El ala oeste de la Casa Blanca, Mujeres Desesperadas y House. Barcelona: Editorial UOC.

\section{Cómo citar este artículo en bibliografías - How to cite this article in bibliographies / references:}

RAYA-BRAVO, I. (2016): "La tendencia hacia la hibridación en el macrogénero extraordinario durante la era hipertelevisiva. Casos de estudio: Galáctica: estrella de combate, Juego de Tronos y American Horror Story". En Revista de la Asociación Española de Investigación de la Comunicación, vol. 3, número 6, pp. 11-18. 